\title{
Minat Berkunjung Wisatawan ke Museum Adityawarman Kota Padang
}

\author{
Fashliya Zurni Effendi', Kurnia Illahi Manvi ${ }^{2}$ \\ ${ }^{1}$ Universitas Negeri Padang \\ ${ }^{2}$ Universitas Negeri Padang \\ email: fashliyaze@gmail.com
}

\begin{abstract}
ABSTRAK
Penelitian ini bertujuan untuk menganalisis Minat Berkunjung Wisatawan Di Museum Adityawarman Kota Padang. Jenis penelitian ini dikategorikan sebagai penelitian kuantitatif dengan menggunakan metode kausal. Sampel penelitian ini merupakan responden yang belum pernah berkunjung di Museum Adityawarman Kota Padang dengan sampel yang berjumlah 94 responden, Teknik pengambilan sampel yang digunakan yaitu non-probability sampling. Information dikumpulkan dengan menggunakan kuesioner tersusun sesuai dengan skala likert yang sudah Uji validitas dan reliabilitas, information dapat dideskripsikan dan diuji untuk keperluan analisis.

Dari hasil penelitian yang telah dilakukan, secara umum dapat diperoleh bahwa analisis preferensi wisata pariwisata di Museum Adityawarman Kota Padang berada pada kategori cukup dengan persentase sebesar $74 \%$. Selanjutnya juga diperoleh hasil berdasarkan indikator sebagai berikut : 1) Ketertarikan persentase tertinggi pada kategori cukup dengan persentase 50\%, 2) Preferensi dengan persentase tertinggi adalah kategori cukup, dengan persentase 44\%, 3)Pencarian informasi persentase tertinggi pada kategori cukup dengan persentase $61 \%$.
\end{abstract}

\section{Kata Kunci : Minat Berkunjung, Wisatawan}




\section{PENDAHULUAN}

Pariwisata merupakan sektor yang berperan penting dalam memajukan penghasilan dari pariwisata di Indonesia. indonesia adalah negara berkembang pesat, dikarenakan Indonesia sebagai negara yang banyak pulau memiliki keberagaman, agama, suku, budaya dan ras, dan bahasa yang dianggap unik [1]. Indonesia adalah negara dengan keindahan alam dan keragaman budaya yang menakjubkan dan terdapatnya banyak objek wisata di berbagai daerah. Industri pariwisata yang cepat perkembangannya dapat memajukan wawasan antar budaya melalui hubungan antara wisatawan dengan masyarakat setempat di mana kawasan wisata tersebut berada, Hal ini memungkinkan pengunjung untuk memahami dan menghormati budaya masyarakat setempat, serta mengetahui lingkungan adat istiadat yang diikuti masyarakat setempat [2]. Salah satunya wisata budaya yang di indonesia yaitu museum. pariwisata dan museum adalah dua hal yang tak dapat dipisahkan satu sama lain [3].

Museum merupakan organisasi yang senantiasa memperhatikan pengunjung dan perkembangannya, tersedia untuk banyak orang, mengumpulkan, menjaga, mempertahankan, dan menampilkan artefak identitas manusia dan lingkungan untuk tujuan pembelajaran, pengetahuan, dan wisata [4]. Kota Padang yang memiliki wisata budaya, Sebagai kawasan yang memiliki wisata budaya maka terdapat salah satu museum yang ada di Kota Padang yaitu Museum Adityawarman. Museum adityawarman merupakan tempat wisata budaya dan wisata edukasi yang merangkum banyak benda koleksi sejarah dari zaman kerajaan hindu, budha dan islam. Museum memiliki berbagai macam jenis koleksi peninggalan sejarah yaitu: Geologika, Biologika, Etnografika, Arkeologika, Historika, Numismatika, Filologika, Keramologika, Seni Rupa, dan Teknologika dan masih banyak lagi koleksi-koleksi peninggalan sejarah di museum adityawarman.

Minat berkunjung memiliki kesamaan dengan minat pembelian [5]. Minat dapat diartikan sebagai dorongan atau keinginan, minat berkunjung berarti keinginan atau ketertarikan seseorang untuk berkunjung ke suatu tempat. Minat berkunjung mempunyai 3 indikator yaitu Ketertarikan, preferensi(prioritas), pencarian informasi[6]. Ada beberapa aspek mempengaruhi minat seorang pengunjung berkunjung adalah, promosi, psikologis, budaya, dan sosial sebelum membeli.[7]. Konsumen dan wisatawan yang memutuskan untuk berkunjung memiliki berbagai pertimbangan, seperti sebelum membeli. Setiap destinasi wisata pasti memiliki nilai yang dapat membangkitkan perasaan pengunjung untuk berkunjung [8]. Data pengunjung Museum Adityawarman Kota Padang Tahun 2020 dilihat pada tabel berikut :

Table 1. Data Pengunjung Museum Adityawarman pada tahun 2020

\begin{tabular}{|c|c|c|c|c|}
\hline NO & BULAN & DEWASA & ANAK-ANAK & JUMLAH \\
\hline 1 & Januari & 2.701 & 1.279 & 3.724 \\
\hline 2 & Februari & 2.154 & 2.446 & 4.484 \\
\hline 3 & Maret & 902 & 832 & 1.734 \\
\hline 4 & April & \multicolumn{3}{|c}{} \\
\cline { 1 - 3 } 5 & Mei & \multicolumn{3}{|c|}{ PSBB } \\
\cline { 1 - 3 } 6 & Juni & 214 & 69 & 283 \\
\hline 7 & Juli & 637 & 213 & 850 \\
\hline 8 & Agustus & 735 & 185 & 920 \\
\hline 9 & September & 548 & 111 & 659 \\
\hline 10 & Oktober & 793 & 178 & 971 \\
\hline 11 & November & 997 & 174 & 1171 \\
\hline 12 & Desember & 1.106 & 327 & 1.433 \\
\hline & & \multicolumn{1}{|l}{} \\
& JUMLAH & 10.787 & 5.805 & 16.592 \\
\hline
\end{tabular}

Sumber : UPTD Museum Adityawarman Provinsi Sumatera Barat (2021) 
Berdasarkan pengamatan pada saat melakukan observasi di museum adityawarman pada bulan Maret 2021 ditemukan beberapa permasalahan terkait dengan minat berkunjung wisatawan, permasalahan pertama terkait ketertarikan yaitu museum adityawarman memiliki bangunan yang khas berbentuk Rumah Gadang, sehingga membuat wisatawan hanya ingin berfoto di depan rumah gadang. Mayoritas alasan wisatawan ingin berkunjung hanya ingin mengetahui bagaimana suasana di museum Adityawarman, singgah berswafoto di depan rumah gadang dan bermain di Taman Melati di lingkungan museum tersebut. Ciri khas dari daya tarik wisata Museum Adityawarman masih kurang ditonjolkan. Seharusnya museum memiliki daya tarik yang mampu memikat wisatawan yang ingin berkunjung, maka hal ini membuat wisatawan tidak merasa bosan. Sehingga menambah minat wisatawan untuk mengunjungi tempat wisata tersebut.

Permasalahan selanjutnya terkait preferensi yaitu bahwa museum belum menjadi pilihan utama bagi wisatawan untuk berlibur, banyak wisatawan mengetahui museum tersebut tetapi belum pernah mengunjunginya. Disaat ada kesempatan wisatawan mengunjungi museum dikarenakan dekat dengan tempat penginapannya atau ada di sebuah kondisi dimana wisatawan memiliki kegiatan untuk mengunjungi museum itu, wisatawan dengan melihat kawasan sekitar museum saja atau di halaman taman melati dan berfoto.

Permasalahan lain terkait pencarian informasi yaitu pencarian informasi yang dilakukan wisatawan sebelum mengunjungi museum tetapi permasalahannya adalah informasi yang belum banyak didapatkan oleh wisatawan. Serta kurangnya informasi yang rinci terkait dengan koleksi museum dan informasi tentang museum sangat minim sehingga membuat bingung dan wisatawan kurang tau dimana bisa mendapatkan informasi detail terkait museum.

\section{METODOLOGI PENELITIAN}

Berdasarkan dari permasalahan dan tujuan yang ingin dicapai, jenis penelitian ini digolongkan penelitian deskriptif kuantitatif. Sampel riset ini merupakan responden yang belum pernah berkunjung di Museum Adityawarman Kota Padang, dan mengetahui keberadaan museum Adityawarman tersebut, dengan sampel berjumlah 94 responden.

Jenis Teknik dalam menentukan sampel digunakan yaitu non probability sampling. Pengumpulan data dilakukan dengan angket terstruktur berdasarkan skala Likert, dan telah diuji validitas dan reliabilitasnya, Data dapat dideskripsikan dan di lakukan analisis. Jenis data penelitian ini terdiri dari data primer dan sekunder [9]. metode analisis data penelitian ini yaitu analisis data statistik deskriptif. Analisis dilakukan dengan membuat tabel dan distribusi frekuensi variabel, untuk mengklasifikasikan masing-masing indikator digunakan rumus rata-rata ideal (Mi), dan standar deviasi (sdi).

\section{HASIL DAN PEMBAHASAN}

\section{A. Hasil Penelitian}

Berdasarkan hasil pengujian dari variabel minat berkunjung berupa angket yang disebarkan kepada 94 responden yang dimana validitas dan reliabilitasnya telah memenuhi syarat dan Jumlah pernyataan yang diberikan sebanyak 16 butir dengan pernyataan dari 3 indikator yang diisi oleh sejumlah responden. Adapun hasil dari olahan data yang telah dilakukan dari penelitian terkait dengan variabel minat berkunjung wisatawan di museum adityawarman adalah sebagai berikut : 
Tabel 1. Distribusi Frekuensi Minat Berkunjung

\begin{tabular}{|c|c|c|c|}
\hline Kategori & Rentang skor & Frekuensi & \% \\
\hline Sangat baik & $\geq 63,99$ & 0 & $0 \%$ \\
\hline Baik & $53,33-<63,99$ & 18 & $19 \%$ \\
\hline Cukup & $\mathbf{4 2 , 6 7 - < 5 3 , 3 3}$ & $\mathbf{7 0}$ & $\mathbf{7 4 \%}$ \\
\hline Buruk & $31,01-<42,67$ & 6 & $6 \%$ \\
\hline Sangat Buruk & $<32,01$ & 0 & $0 \%$ \\
\hline \multicolumn{2}{|c|}{ Jumlah } & $\mathbf{9 4}$ & $\mathbf{1 0 0 \%}$ \\
\hline
\end{tabular}

Berdasarkan tabel di atas dapat dijelaskan dari 94 responden untuk variabel Minat Berkunjung dikelompokan menjadi kategori sangat baik 0\%, baik 19\%, Cukup 74\%, buruk 6\%, dan sangat buruk 0\%. Berdasarkan perhitungan statistik variabel Minat Berkunjung berada pada klasifikasi skor 42,67 - <53,33 menunjukan kategori cukup dengan persentase 74\%.

Selanjutnya minat berkunjung yang akan diklasifikasikan per indikator yaitu sebagai berikut :

1. Ketertarikan

Berikut deskripsi data untuk indikator ketertarikan setelah dilakukannya penelitian dan hasilnya adalah sebagai berikut:

Tabel 2. Deskripsi Data Indikator Ketertarikan

\begin{tabular}{|c|c|c|c|}
\hline Kategori & Rentang skor & Frekuensi & \% \\
\hline Sangat baik & $\geq 24$ & 5 & $5 \%$ \\
\hline Baik & $20-<24$ & 33 & $35 \%$ \\
\hline Cukup & $\mathbf{1 6}-<\mathbf{2 0}$ & $\mathbf{4 7}$ & $\mathbf{5 0 \%}$ \\
\hline Buruk & $12-<16$ & 9 & $10 \%$ \\
\hline Sangat Buruk & $<12$ & 0 & $0 \%$ \\
\hline \multicolumn{2}{|c|}{ Total } & $\mathbf{9 4}$ & $\mathbf{1 0 0 \%}$ \\
\hline
\end{tabular}

Pada tabel diatas diketahui bahwa indikator ketertarikan sebanyak 5\% termasuk kategori sangat baik, $35 \%$ baik, $50 \%$ cukup, $10 \%$ buruk, dan $0 \%$ sangat buruk. hasil pengolahan data menunjukan bahwa jawaban responden tentang indikator ketertarikan di Museum Adityawarman Padang termasuk dalam kategori Sangat Baik dengan tingkat 50\%.

2. Preferensi

Berikut deskripsi data untuk indikator preferensi setelah dilakukannya penelitian dan hasilnya adalah sebagai berikut:

Tabel 3. Deskripsi Data Indikator Preferensi

\begin{tabular}{|c|c|c|c|}
\hline Kategori & Kelas Interval & Frekuensi & $(\%)$ \\
\hline Sangat baik & $\geq 15,99$ & 4 & $4 \%$ \\
\hline Baik & $13,33-<15,99$ & 26 & $28 \%$ \\
\hline Cukup & $10,67-<13,33$ & 41 & $44 \%$ \\
\hline Buruk & $8,01-<10,67$ & 20 & $21 \%$ \\
\hline Sangat Buruk & $<8,01$ & 3 & $3 \%$ \\
\hline \multicolumn{2}{|c|}{ Total } & 94 & $100 \%$ \\
\hline
\end{tabular}

Seperti terlihat pada datel diatas indikator Preferensi sebanyak 4\% kategori sangat baik, 28\% baik, 44\% cukup, 21\% kategori buruk, 3\% sangat buruk. Dari hasil penelitian terhadap indikator preferensi dapat disimpulkan bahwa persentase tertinggi terdapat pada kategori cukup, dengan persentase sebesar $41 \%$. 


\section{Pencarian informasi}

Berikut deskripsi data untuk indikator Pencarian informasi setelah dilakukannya penelitian diperoleh hasil seperti tabel berikut :

Tabel 4. Deskripsi Data Indikator Pencarian Informasi

\begin{tabular}{|c|c|c|c|}
\hline Kategori & Kelas Interval & Frekuensi & \% \\
\hline Sangat baik & $\geq 24$ & 2 & $2 \%$ \\
\hline Baik & $20-<24$ & 22 & $23 \%$ \\
\hline Cukup & $\mathbf{1 6}-<\mathbf{2 0}$ & $\mathbf{5 7}$ & $\mathbf{6 1 \%}$ \\
\hline Buruk & $12-<16$ & 12 & $13 \%$ \\
\hline Sangat Buruk & $<12$ & 1 & $1 \%$ \\
\hline \multicolumn{2}{|c|}{ Total } & $\mathbf{9 4}$ & $\mathbf{1 0 0 \%}$ \\
\hline
\end{tabular}

Pada tabel diatas diketahui bahwa indikator Pencarian informasi sebanyak 2\% kategori Sangat baik, 23\% Baik, 61\% kategori Cukup, 13\% Buruk, dan 1\% Sangat buruk. Dari hasil penelitian terhadap indikator pencarian informasi, dapat disimpulkan bahwa persentase tertinggi terdapat pada kategori cukup, dengan persentase sebesar $61 \%$.

\section{B. Pembahasan}

Berdasarkan penelitian yang dilakukan, telah diperoleh hasil dan gambaran minat berkunjung wisatawan di Museum Adityawarman Kota Padang. Berdasarkan olahan data dari penyebaran angket dengan jumlah pernyataan sebanyak 16 buah pernyataan, maka dapat dijelaskan secara umum minat berkunjung di Museum Adityawarman Kota Padang menunjukkan bahwa hasil persentase penilaian secara dominan berada pada kategori cukup dengan persentase sebesar $74 \%$ serta rentang skor berada pada 42,67 - <53,33.

Hasil deskripsi data masing-masing indikator dapat dibagi menjadi beberapa kategori sebagai berikut:

\section{1) Ketertarikan}

Ketertarikan diartikan sebagai kondisi dimana konsumen cenderung membeli atau menginginkan produk yang berbeda dengan produk lainnya. Hasil dari penelitian bahwa Persentase tertinggi pada kategori Cukup dengan persentase 50\% Dapat disimpulkan responden cukup memiliki ketertarikan untuk minat berkunjung ke Museum Adityawarman. Ketertarikan merupakan awal dari keputusan berkunjung wisatawan ke suatu destinasi wisata. Wisatawan akan mencari informasi terkait destinasi wisata yang mereka minati tersebut[10]. Suatu keputusan berkunjung dapat dipengaruhi oleh banyak faktor, seperti usaha dari pemasar untuk mempengaruhi minat atau keputusan berkunjung wisatawan[11].

\section{2) Preferensi}

Situasi yang menggambarkan seseorang tertarik pada suatu produk akan mengabaikan kebutuhan lain atau ingin memperoleh produk yang diminatinya. Persentase tertinggi pada kategori cukup dengan persentase $44 \%$, disimpulkan bahwa responden cukup baik untuk menjadikan Museum Adityawarman sebagai pilihan untuk wisata. Informasi yang di dapat pengunjung tentang suatu destinasi wisata, akan menjadi bahan perbandingan atau pertimbangan jadi atau tidak berkunjung ke destinasi wisata tersebut [12].

\section{3) Pencarian Informasi}

Seberapa sering konsumen mencari informasi produk. Konsumen yang tertarik dengan produk akan mencari kelebihan dan kekurangan produk tersebut[13]. Persentase tertinggi pada kategori 
Cukup Dengan persentase $61 \%$ disimpulkan bahwa responden cukup dalam pencarian informasi Museum Adityawarman Kota Padang.

Minat berkunjung merupakan kelakukan yang ditampilkan dalam menanggapi suatu objek yang menentukan kesediaan pengunjung untuk berkunjung artinya sesuatu yang dihasilkan melalui perilaku optimis pembeli akan memperoleh yang mereka perlukan, sehingga pembeli dapat membeli [14].

Wisatawan mendapatkan dan mengetahui informasi yang lebih baik dan positif sehingga wisatawan dapat merasakannya dan itu dapat meningkatkan minat berkunjung ke Museum Aditywarman Kota Padang, begitu pula sebaliknya jika wisatawan mendapatkan dan mengetahui informasi negatif sehingga dapat dirasakan oleh wisatawan maka dapat Kurangi minat berkunjung ke Museum Aditywarman Kota Padang.

Museum adalah objek wisata budaya, fungsi dan perannya bukan hanya sebagai tempat menyimpan barang antik, sehingga banyak orang akan lebih tertarik untuk berkunjung ke Museum Adityawarman Kota Padang. Museum Adityawarman Kota Padang harus bisa menunjukkan kepada masyarakat nilai koleksi yang tersimpan agar pengunjung tertarik untuk berkunjung ke Museum Adityawarman Kota Padang. Kurator museum harus mampu beradaptasi khususnya terkait dengan penyebaran informasi, pemanfaatan teknologi digital dan jejaring sosial, sehingga pengunjung dapat mengunjungi khazanah museum. Dari hasil penelitian di atas dapat Disimpulkan bahwa keadaan minat berkunjung di Museum bagi wisatawan yang belum berkunjung ke Museum Adityawarman Kota Padang secara keseluruhan dikategorikan dalam keadaan cukup baik untuk berminat mengunjungi Museum Adityawarman Kota Padang.

\section{KESIMPULAN}

Hasil penelitian tentang Analisis Minat Berkunjung Wisatawan di Museum Adityawarman Kota Padang, maka disimpulkan secara umum keseluruhan hasil penelitian berada pada rentang interval antara 42,67 - <53,33 dengan kategori buruk dengan persentase penilaian sebesar $74 \%$. berlandaskan indikator variabel yaitu sebagai berikut:

1. Indikator ketertarikan hasil yang tertinggi adalah kategori cukup, dan persentase penilaian responden adalah 50\%..

2. Indikator Preferensi hasil yang tertinggi adalah kategori cukup, dan persentase penilaian responden adalah $44 \%$.

3. Indikator Pencarian informasi hasil yang tertinggi adalah kategori cukup, dan persentase penilaian responden adalah $61 \%$. 


\section{DAFTAR PUSTAKA}

[1] A. Prabhawati, "Upaya Indonesia dalam Meningkatkan Kualitas Pariwisata Budaya Melalui Diplomasi Kebudayaan,” J. Tour. Creat., vol. 2, no. 2, pp. 158-177, 2018.

[2] S. Sugiyarto and R. J. Amaruli, "Pengembangan Pariwisata Berbasis Budaya dan Kearifan Lokal," J. Adm. Bisnis, vol. 7, no. 1, p. 45, 2018, doi: 10.14710/jab.v7i1.22609.

[3] I. junaid, "Museum dalam perspektif pariwisata dan pendidikan," no. November, pp. 1-15, 2018, doi: 10.31219/osf.io/dm2hj.

[4] S. Vidiardi, "Pengembangan Museum Virtual Interaktif Menggunakan Teknologi Desktop Virtual Reality Pada Museum Ranggawarsita," Univ. Negeri Semarang, pp. 1-99, 2015.

[5] F. Aprilia, "PENGARUH WORD OF MOUTH TERHADAP MINAT BERKUNJUNG SERTA DAMPAKNYA PADA KEPUTUSAN BERKUNJUNG (Survei pada Pengunjung Tempat Wisata âJawa Timur Park 2â Kota Batu)," J. Adm. Bisnis S1 Univ. Brawijaya, vol. 24, no. 1, p. 86013, 2015.

[6] A. Ramadhan, "PENGARUH CITY BRANDING TERHADAP MINAT BERKUNJUNG SERTA DAMPAKNYA PADA KEPUTUSAN BERKUNJUNG (Survei pada Wisatawan Kota Surabaya 2015)," J. Adm. Bisnis S1 Univ. Brawijaya, vol. 28, no. 2, p. 86456, 2015.

[7] D. Stie, H. Agus, S. Bukittinggi, and S. Barat, "FAKTOR-FAKTOR YANG MEMPENGARUH MINAT WISATAWAN Hariman Syaleh * PENDAHULUAN Pariwisata menyimpan potensi yang besar, baik yang telah maupun yang belum diberdayakan . Melihat fenomena yang maraknya pecinta wisata dari berbagai kalangan . Dengan memilik in,” vol. XX, no. 2, pp. 126134, 2016.

[8] D. Anggraeni, F. Ekonomi, D. A. N. Bisnis, and U. Dinamika, "Citra Destinasi Dan Daya Tarik Terhadap Minat," 2020.

[9] I. Imron, "Analisa Pengaruh Kualitas Produk Terhadap Kepuasan Konsumen Menggunakan Metode Kuantitatif Pada CV. Meubele Berkah Tangerang,” Indones. J. Softw. Eng., vol. 5, no. 1, pp. 19-28, 2019, doi: 10.31294/ijse.v5i1.5861.

[10] S. Filma and H. Suyuthie, "PENGARUH PROMOSI TERHADAP KEPUTUSAN BERKUNJUNG WISATAWAN KE OBJEK WISATA GREEN HOUSE LEZATTA KABUPATEN AGAM," J. Kaji. PARIWISATA DAN BISNIS PERHOTELAN, vol. 1, no. 2, pp. 72-76, 2020, doi: https://doi.org/10.24036/jkpbp.v1i2.6772.

[11] Y. Abrian, A. Adrian, and R. Surendra, "Analysis of Factors Affecting Guest Decision in Purchase of Room Service in Hotel 'Grand Inna Padang," J. Bus. Hosp. Tour., vol. 5, no. 2, pp. 193-200, 2019, doi: http://dx.doi.org/10.22334/jbhost.v5i2.165.

[12] Wira Novrilla Ananda Putri and Y. Abrian, "PENGARUH HARGA DAN LOKASI TERHADAP KEPUTUSAN PEMBELIAN KAMAR DI GRAND ROYAL DENAI HOTEL BUKITTINGGI Wira Novrilla Ananda Putri1, Youmil Abrian2 Program Studi D4 Manajemen Perhotelan Fakultas Pariwisata Dan Perhotelan Universitas Negeri Padang E-mail : wir," J. Pendidik. Dan Kel., vol. 10, no. 1, pp. 116-128, 2018, doi: 10.1017/CBO9781107415324.004.

[13] Oktaviani.J, PENGARUH ELECTRONIC WORD-OF-MOUTH DAN CITRA DESTINASI TERHADAP KEPUTUSAN BERKUNJUNG MELALUI MINAT BERKUNJUNG SEBAGAI VARIABEL INTERVENING (Studi pada Obyek Wisata Pulau Panjang Kabupaten Jepara), vol. 51, no. 1. 2018.

[14] M. L. Bachtiar and M. Arif Wibowo, "Pengaruh Strategi Bauran Pemasaran Terhadap Minat Berkunjung Kembali DI Objek Wisata Pantai Kabupaten Gunung Kidul," J. Manaj. Bisnis Indones., vol. 5, no. 1, pp. 40-49, 2016. 